\title{
Normal and Neoplastic Stem Cells
}

\author{
Melissa N. McCracken, $, 1,2,3,5$ Benson M. George, ${ }^{1,2,3,5}$ Kevin S. Kao, ${ }^{1,2}$ Kristopher \\ D. Marjon, ${ }^{1,2,3}$ TAL Raveh, ${ }^{1}$ and Irving L. Weissman ${ }^{1,2,3,4}$ \\ ${ }^{1}$ Institute for Stem Cell Biology and Regenerative Medicine, Stanford University School of Medicine, \\ Stanford, California 94305 \\ ${ }^{2}$ Ludwig Center for Cancer Stem Cell Research and Medicine, Stanford University School of Medicine, \\ Stanford, California 94305 \\ ${ }^{3}$ Stanford Cancer Institute, Stanford University School of Medicine, Stanford, California 94305 \\ ${ }^{4}$ Department of Pathology, Stanford University Medical Center, Stanford, California 94305 \\ Correspondence: irv@stanford.edu
}

\begin{abstract}
A stem cell is broadly defined as a cell that retains the capacity to self-renew, a feature that confers the ability to continuously make identical daughter cells or additional cells that will differentiate into downstream progeny. This highly regulated genetic program to retain "stemness" is under active investigation. Research in our laboratory has explored similarities and differences in embryonic, tissue-specific, and neoplastic stem cells and their terminally differentiated counterparts. In this review, we will focus on the contributions of our laboratory, in particular on the studies that identified the mouse hematopoietic stem cell (HSC) and the human leukemic stem cell. These studies have led to significant improvements in both preclinical and clinical research, including improved clinical bone marrow transplantation protocols, isolation of nonleukemic HSCs, a cancer immunotherapy currently in clinical trials, and development of a HSC reporter mouse. These studies and the current follow-up research by us and others will continue to identify the properties, function, and regulation of both normal and neoplastic stem cells.
\end{abstract}

Over the last 40 years our research has focused on understanding normal and neoplastic stem cells. This review will cover the fundamental discoveries in defining similarities and differences between malignant cells and their healthy counterparts to further understand how to treat and cure hematologic malignancies.

The defining trait of stem cells, unlike most terminally differentiated cells within the body, is their ability to selfrenew. Throughout an animal's life span these tissue-specific stem cells divide and self-renew, whereas daughter cells replace and replenish dead and/or dying terminally differentiated cells. One of the earliest demonstrations of this phenomenon was in bone marrow transplantation (BMT), when animals that were lethally irradiated were rescued by transplantation of healthy nonirradiated bone marrow (Lorenz et al. 1951; Ford et al. 1956). Early studies in our laboratory expounded on these findings with experiments focused on the hematopoietic system in mice. We worked to identify key surface markers that would allow for the isolation and transplantation of pure hematopoietic stem cells (HSCs). Studies demonstrated that only purified HSCs are capable of long-term selfrenewal and complete replacement and replenishment of all blood subsets in normal homeostasis and after transplantation. By isolating the long-term HSC, we provided a method for how to replace the hematopoietic compartment after chemotherapy, radiation, or antibody-based bone marrow depletion without complications that are observed in whole bone marrow transplantation (Czechowicz and Weissman 2011; Muller et al. 2012; Chhabra et al. 2016). As discussed in further detail below, transplantation of pure HSCs removes potentially deleterious contaminating cells such as hematological and nonhematological malignant cells or alloreactive $\mathrm{T}$ cells from donors.

In cancer, the ability to self-renew is unlocked by a fraction of malignant cells, which are then able to selfrenew and maintain a stem-like population, similar to HSCs. These self-renewing malignant cells are termed cancer stem cells (CSCs) or leukemic stem cells (LSCs). Initial studies for identifying a LSC began with our work on chronic myelogenous leukemia (CML) and acute myeloid leukemia (AML) (Miyamoto et al. 2000; Jamieson et al. 2004a,b; Abrahamsson et al. 2009; Majeti et al. 2009a). We studied primary patient samples to determine key differences between healthy HSCs and their progeny compared with LSCs and blast cells. Several key findings included the identification of LSC markers, identification of how malignant mutations are acquired and retained within the LSC pool, and the identification of CD47 as a "do not eat me" cell surface marker used by all malignancies. In AML, up-regulation of CD47 was observed on almost all cells from a large portion of primary patient samples (Majeti et al. 2009b). Later studies

\footnotetext{
${ }^{5}$ These authors contributed equally to this work.

(C) 2016 McCracken et al. This article is distributed under the terms of the Creative Commons Attribution-NonCommercial License, which permits reuse and redistribution, except for commercial purposes, provided that the original author and source are credited.
} 
found that solid tumors also increase their CD47 expression when compared with normal counterpart cells (Willingham et al. 2012). Through in vitro and in vivo studies we determined that the antibody blockade of CD47 increased phagocytosis and aided in the removal of cancerous cells.

In this review, we will cover seminal discoveries made by our laboratory and others on identifying the HSC, how this led to the discovery of the LSC, and how understanding similarities and differences between these two populations can identify new therapeutic targets.

\section{ELUCIDATING THE HEMATOPOIETIC HIERARCHY}

The HSC is the most well-characterized stem cell in both mice and humans. Studying them has provided a wealth of information in the fields of developmental biology and stem cell biology. Additionally, HSCs have been by far the most clinically translated multipotent cell type, with the first successful bone marrow transplant being reported in 1959 (Thomas et al. 1959). Today, HSCs remain at the forefront of regenerative medicine, as they are being leveraged to battle cancer, correct genetic disorders, tame autoimmune diseases, and tackle a host of other pathologies. However, these advances hinge on basic science discoveries that led to the isolation of the HSC as well as its downstream progenitor cells, which give rise to more than 10 distinct mature cell types.

Interest around HSCs began growing in the mid-20th century when Jacobson et al. (1951) showed that mice could be protected from lethal irradiation by shielding the spleen. This early work alluded to a humoral factor secreted by the spleen that could stimulate reconstitution of the damaged bone marrow. Later studies utilizing bone marrow transplantation and tracking clonogenicity via chromosomal abnormalities shed light on the possibility of a self-renewing cell type, rather than a soluble factor, that could give rise to blood cells (Lorenz et al. 1951; Ford et al. 1956). Upon this finding, physicians began to consider bone marrow transplantation as a therapy for radiation toxicity (Thomas et al. 1957). Soon the notion that a single purified population with the ability to self-renew and give rise to multiple differentiated cell types began to gain traction. However, strong evidence for this biological phenomenon was not brought forward until the colony forming assays established by Till and McCulloch (Till 1961; Becker et al. 1963; Wu et al. 1967). Since the work of these pioneering scientists and many others, our laboratory has focused on isolating pure hematopoietic stem and progenitor cells. Much of this review will focus on our contributions to the field of stem cell biology in the context of normal hematopoiesis and cancer.

To study and characterize the HSCs required purifying this population from heterogeneous bone marrow. Two critical innovations that enabled this task were the development of antibodies toward distinct cell surface antigens and the coupling of these antibodies to fluorescent molecules for fluorescence-activated cell sorting (FACS). In pursuit of identifying early B-lymphocyte progenitors, Muller-Sieburg et al. (1986) used a two-color FACS strategy to isolate B-cell precursors and a phenotypic pluripotent stem cell population. The authors utilized the Whitlock-Witte culture system where potential progenitors are cocultured with pre-established bone marrow-derived stromal cells (Whitlock and Witte 1982). With this system, the authors isolated B220- cells, knowing that pre-B cells expressed B220, and cultured them to test their capacity to generate long-term cultures yielding mature B cells. After successfully demonstrating that $\mathrm{B}_{2} 20^{-}$cells could generate long-term cultures whereas $\mathrm{B} 220^{+}$cells could not, the authors then tried to further refine their precursor population using antibodies against antigens on differentiated cell types, known as lineage markers.

Antibodies against CD4, CD8, Gr1, Mac1, and B220 allowed the authors to negatively select for differentiated T-cell, B-cell, granulocyte, and monocyte populations. Additionally, they utilized Thy1.1, a marker highly expressed on T cells, for positive selection. Reports showed that this marker was expressed in bone marrow cells and that Thy $1.1^{+}$cells gave rise to splenic colonies when injected into irradiated mice, which was considered a criterion for hematopoietic multipotency (Basch and Berman 1982). After isolating cells negative for lineage markers with low expression of Thy1.1, referred to as Thy $1.1^{\text {lo }}$ Lin $^{-}$, Muller-Sieburg et al. (1986) showed these cells gave rise to T, B, myeloid, and erthyroid cells via in vitro and in vivo methods. This population, which represented $0.1 \%-0.2 \%$ of bone marrow, also rescued lethally irradiated animals by fully reconstituting their hematopoietic system.

In a landmark paper, Spangrude et al. (1988) were able to further purify this pluripotent hematopoietic stem population using an antibody to Sca-1. Using Thy $1.1^{\text {lo }}$ Lin $^{-}$ Sca- ${ }^{+}$(TLS) cells, the authors saw a 1000-fold enrichment for splenic colony forming units compared with whole bone marrow; thus, these cells were enriched for stem cell activity. Intrathymic injection of this purified population resulted in thymic colonies with as few as four cells, whereas previous reports had required 5000-8000 whole bone marrow cells to recapitulate this finding. After intravenous injection into a lethally irradiated animal, 40 TLS cells contributed to $50 \%$ of leukocyte chimerism at 6 weeks. The donor cells were positive for lymphoid and myeloid markers. Finally, approximately 30 cells could be injected to provide $50 \%$ survival of lethally irradiated animals, compared with $1.3 \times 10^{4}$ to $3.3 \times 10^{4}$ whole bone marrow cells. These data represented the most purified population of cells to achieve two of the hallmarks of an HSC: multilineage reconstitution and hematopoietic rescue of lethally irradiated animal. The final hallmark, long-term self-renewal, was shown by Smith et al. (1991). In their experiments, mice were transplanted with a single TLS cell and sacrificed 8 weeks later to isolate the donor TLS cells. These donor cells were then secondarily transferred into another le- 
thally irradiated animal. The second transplants resulted in multilineage chimerism, which could only be possible if the initial single-cell transplant resulted in self-renewal of new HSCs.

The question of whether these TLS cells were the purest HSCs was called into question by many. However, their heterogeneity was not shown until they were fractioned by rhodamine-123 (Rh-123) staining and shown to have different functional capacity in vivo (Spangrude and Johnson 1990). Positive staining with Rh-123, which preferentially binds mitochondria, is indicative of a cell which is in an active state. The authors found that cells with lower Rh-123 staining, or quiescent cells, had a 20fold-higher capability of creating splenic colonies than the higher Rh-123 population. Our laboratory was able to further refine the phenotypic HSCs based on observations that mutations in the loci for steel factor, also known as stem cell factor, and its receptor, c-Kit, in mice resulted in reduced hematopoietic activity and anemia (Russell 1979). Using antibodies against c-Kit, Ikuta and Weissman (1992) isolated the c-Kit ${ }^{+}$subset of TLS bone marrow cells and showed that low-dose transplantation of this population was capable of long-term multilineage hematopoietic reconstitution, whereas the negative fraction resulted in no donor chimerism 10 and 15 weeks after injection.

Identifying c-Kit as a marker of stemness was a major advancement; however, our laboratory, as well as others, continued to strive to identify the long-term HSC (LT-HSC). Although TLS cells produced multilineage reconstitution and rescued lethally irradiated mice, Uchida et al. (1993) estimated that only 1 out of 22 of these phenotypic HSCs initiated blood cell production in vivo. Soon after, the identification of CD34 as a negative marker of the LT-HSC helped refine the population and also provided an interesting deviation from human HSC biology, as our group had previously reported CD34 as a marker for human multipotent hematopoietic precursors (Baum et al. 1992; Osawa et al. 1996). $\mathrm{CD}^{+}{ }^{+}{\mathrm{c}-\mathrm{Kit}^{+}}^{+} \mathrm{Sca}^{+} \mathrm{Lin}^{-}$cells could provide early hematopoietic reconstitution, but it was transient, whereas the $\mathrm{CD} 34^{-/ \text {lo }}$ fraction provided sustained reconstitution.

Continuing to immunophenotype the LT-HSC has also allowed our group to uncover downstream progenitors. The use of Flk2 has enabled us to identify three fractions within the TLS c-Kit ${ }^{+}$subset (Christensen and Weissman 2001). Thy $1.1^{\text {lo }} \mathrm{Flk}^{-}$cells were shown to be LT-HSC, whereas Thy $1.1^{\text {lo }} \mathrm{Flk} 2^{+}$cells were identified as shortterm HSCs (ST-HSCs), and Thy $1.1^{-}$Flk2 ${ }^{+}$were further downstream from the ST-HSCs. As the expression of Flk2 increased and Thy1.1 decreased, there was a progressive loss of self-renewal capacity, indicating progressive differentiation. Combining Flk2 with the lineage marker antibodies allowed identification of LT-HSCs by using three-color sorting, with the other two channels being used for Scal and c-Kit. By minimizing the number of channels needed to isolate these cells, additional surface markers could be used to further characterize the population. Kiel et al. (2005) were also able to minimize the number of markers needed to identify LT-HSCs and multipotent hematopoietic progenitors (MPPs) with an approach involving the signaling lymphocyte activation molecule (SLAM) family members. This work, combined with our previous findings and that of others mentioned earlier, characterized the LT-HSC as $\mathrm{Lin}^{-} \mathrm{c}_{-\mathrm{Kit}^{+}} \mathrm{Scal}^{+}$ Flk2 ${ }^{-} \mathrm{CD} 34^{-} \mathrm{CD} 150^{+}$.

Identifying the LT-HSC and its immediate downstream progenitors has provided us with the tools to further characterize the hematopoietic hierarchy. (Kondo et al. (1997) identified the first oligopotent progenitor cell by isolating a murine population that was lymphoid-restricted. This work was initiated by the observation that IL-7 played a pivotal role in both $\mathrm{T}$ - and B-cell development. The authors looked for expression of IL-7R $\alpha$ in $\mathrm{Lin}^{-}$cells and isolated a Lin ${ }^{-}$IL-7R $\alpha^{+}$Thy $1.1^{-}$Sca- $^{\text {lo }}{\mathrm{c}-K i t^{l o}}^{\text {lo }}$ population. When these cells were transplanted into lethally irradiated congenic mice, the only donor-derived cells were $\mathrm{B}_{2} 20^{+}$or $\mathrm{CD}^{+}$. Donor chimerism in these lineages was highest at 5 weeks but steadily decreased over time, indicating the inability of the common lymphoid progenitor (CLP) to self-renew. Additionally, when the CLP was transplanted into immunodeficient mice, natural killer $(\mathrm{NK})$ cells could be found in the spleen. These findings confidently indicated that the CLPs were irreversibly restricted to producing all the mature lymphoid subsets while lacking the ability to differentiate into myeloid cells.

Our group was later able to isolate the common myeloid progenitor (CMP) population, which together with the CLP cells represented a definitive branch point in early hematopoiesis and the transition from multipotency to oligopotency. Given that CLP cells were IL-7R $\alpha^{+}$, Akashi et al. (2000) intuitively searched the IL-7R $\alpha^{-}$ population to identify cells with the ability to differentiate into the myeloid and erythroid subsets. The IL-7R $\alpha^{-}$ fraction of $\mathrm{Lin}^{-} \mathrm{c}-\mathrm{Kit}^{+}$cells were capable of substantial myeloerythroid colony formation activity; however, within this population the Sca- $1^{+}$cells contained HSC activity and thus needed to be removed to fully purify a lineage-restricted oligopotent cell. The subsequent IL-7R $\alpha^{-} \mathrm{Lin}^{-}{\mathrm{c}-\mathrm{Kit}^{+}}^{+} \mathrm{Sca}-{ }^{-}$could be further subdivided by Fc $\gamma \mathrm{R}$ and CD34. The authors demonstrated that the FcyR ${ }^{\text {lo }} \mathrm{CD}_{3} 4^{+}$cells were identical to HSCs in colony forming assays. However, the Fc $\gamma \mathrm{R}^{\text {hi }} \mathrm{CD} 34^{+}$ cells formed only granulocytes or macrophages in vitro and in vivo, whereas the Fc $\gamma \mathrm{R}^{\text {lo }} \mathrm{CD} 34^{-}$cells exclusively formed megakaryocytes and erythrocytes. Based on these findings, the authors coined the FcyR ${ }^{\text {hi }} \mathrm{CD} 34^{+}$ population as granulocyte/macrophage lineage-restricted progenitors (GMPs) and the Fc $\gamma \mathrm{R}^{\mathrm{lo}} \mathrm{CD} 34^{-}$as megakaryocyte/erythrocyte lineage-restricted progenitors (MEPs).

Over time, our laboratory has further helped isolate, characterize, and define the HSC and its downstream progenitors previously shown in Seita and Weissman (2010). We have continued to build upon these findings within the mouse system to ultimately understand properties that govern stemness, HSC maintenance, and the HSC niche. 


\section{Hoxb5 AS THE DEFINITIVE MARKER FOR LONG-TERM HSCS IN MICE}

Since their first isolation (Spangrude et al. 1988), our characterization of the immunologic profile of HSCs has become increasingly precise with the identification of specific cell surface markers (Osawa et al. 1996; Christensen and Weissman 2001; Kiel et al. 2005; Fathman et al. 2014). However, our present definition of HSCs still remains limited in its ability to clearly distinguish phenotypic subsets within the HSC population-namely, the long-term and short-term HSCs. In addition, the need for a complex antibody cocktail to discriminate HSCs remains incompatible with microscopy, limiting our abilities to visualize the anatomical position of the HSC and its interactions with neighboring cells within the bone marrow. As a result, in recent years, numerous groups have generated fluorescent reporter mice to overcome these limitations and better characterize HSCs and their interactions within the bone marrow microenvironment (Hills et al. 2011; Gazit et al. 2014; Acar et al. 2015).

Through unbiased multistep screening, our group has managed to identify a single gene, homeobox B5 (Hoxb5, Hox 2.1), whose expression in the bone marrow is exclusive to the HSC transcriptome (Chen et al. 2016). Utilizing the Gene Expression Commons database (Seita et al. 2012) to compare gene expression across 28 distinct hematopoietic populations and eight bone and stromal populations, we were able to obtain a list of 45 candidate HSC-specific genes. To ensure that our candidates could be detected both by flow cytometry and microscopy, we utilized a previously generated Bmi-1-eGFP knock-in reporter mouse (Hosen et al. 2007), in which eGFP expression is detectable in the HSC population. We performed RNA-seq on hematopoietic cells from this animal to estimate the minimal fragments per kilobase of transcript per million mapped reads (FPKM) value necessary for detection. Based off of this, we concluded that a minimal FPKM value of $\sim 20$ would be necessary to detect a single copy of eGFP. However, as this criterion would have excluded all potential candidates, we designed a targeting construct containing three copies of mCherry to amplify fluorescent signal, lowering our estimated detection threshold to $\sim 7$. Combining this strategy with RNAseq of immunophenotypic HSCs (pHSCs) $\left(\mathrm{Lin}^{-} \mathrm{c}-\mathrm{Kit}^{+-}\right.$ Sca- $1^{+}$Flk- $2^{-} \mathrm{CD} 34^{-/ 1 \mathrm{lo}} \mathrm{CD} 150^{+}$), multipotent progenitors subset $\mathrm{A}\left(\mathrm{Lin}^{-} \mathrm{c}-\mathrm{Kit}^{+} \mathrm{Sca}-1^{+} \mathrm{Flk}-2^{-} \mathrm{CD} 34^{+} \mathrm{CD} 150^{+}\right)$, and multipotent progenitors subset $\mathrm{B}\left(\mathrm{Lin}^{-} \mathrm{c}-\mathrm{Kit}^{+} \mathrm{Sca}-{ }^{+} \mathrm{Flk}-\right.$ $2^{-} \mathrm{CD} 34^{+} \mathrm{CD} 150^{-}$), from $\mathrm{C} 57 / \mathrm{B} 6 \mathrm{~J}$ mice, we were able to quantify the FPKM value of each candidate gene and narrow down our list to three candidates-Hoxb5, Rnf208, and Smtnll. Given that numerous groups have reported heterogeneity within the phenotypic HSC (pHSC) population, we rationalized that the ideal pan-HSC marker would possess a bimodal expression pattern, with differences in gene expression potentially implicating diversity within the population. Through single-cell quantitative polymerase chain reaction (qPCR), we managed to identify Hoxb5 as the only candidate within the HSC transcriptome that satisfied all the criteria of our multistep screen.
By engineering an in-frame triple-mCherry Hoxb5 knock-in mouse (Hoxb5-tri-mCherry), we have managed to design a model system whereby Hoxb5-expressing HSCs can be isolated and visualized via endogenous fluorescent signal. To validate the specificity of this reporter, we isolated bone marrow from 12-wk-old reporter mice and evaluated the mCherry expression in various progenitor and differentiated cell populations. From this we observed mCherry expression in $21.8 \pm 0.90 \%$ of pHSCs, $1.88 \pm 0.64 \%$ of MPPs, and no expression elsewhere in the bone marrow (Chen et al. 2016).

The two hallmarks of a HSC are its ability to self-renew and its ability to give rise to all lineages of blood cells. As such, the gold standard of evaluating whether or not a cell is truly a HSC is the transplantation assay, with successful engraftment imparting multilineage reconstitution. Within our current understanding of HSC biology, there exist two subtypes of HSCs, short-term (ST) and long-term (LT), with the latter able to successfully undergo serial transplantation. To validate our finding of Hoxb5 as a marker for HSCs, we isolated mCherry ${ }^{+}$ and mCherry ${ }^{-}$cells within the pHSC population from the bone marrow of 12-wk-old reporter mice and transplanted them into lethally irradiated recipients. As hypothesized, the mCherry ${ }^{+}$cells were able to endow multilineage reconstitution of the hematopoietic system, while the mCherry ${ }^{-}$cells mostly conferred lymphoid reconstitution, indicative of a lymphoid-biased HSC or MPP phenotype. To further evaluate the biology of our mCherry ${ }^{+}$pHSCs, after 16 weeks we isolated whole bone marrow from the primary recipients and transplanted them into lethally irradiated hosts. Strikingly, in our secondary transplantation setting, only the whole bone marrow from $\mathrm{mCherry}^{+}$primary recipients was able to give robust multilineage reconstitution, validating Hoxb5 as a marker of LT-HSCs.

By antibody-based methods (Kiel et al. 2005; MendezFerrer et al. 2010) and microscopy-based detection of HSCs in fluorescent reporter mice (Acar et al. 2015), numerous groups over the years have previously reported that HSCs reside near blood vessels. To validate these findings, we utilized a solvent-based clearing technique - CUBIC - to diminish heme-derived autofluorescence within bone marrow plugs (Susaki et al. 2014) and clarify the tissue for whole-mount imaging. Strikingly, we have managed to reveal a near-homogenous perivascular niche for LT-HSCs, with $>94 \%$ of LT-HSCs being directly attached to vascular endothelial (VE)-cadherin ${ }^{+}$ cells.

With our discovery of Hoxb5 as a marker for murine LT-HSCs, numerous secondary questions must be answered. Namely, does Hoxb5 have a functional role in regulating the capacity for self-renewal or multipotency in LT-HSCs, and if so are variable levels in gene expression indicative of progression in the hematopoietic hierarchy? In addition, at what point in development do hematopoietic precursors or HSCs begin expressing Hoxb5, and how do these cells function in native hematopoiesis? Lastly, does an equivalent genetic marker exist in human HSCs, and if so how can we leverage this to 
study normal hematopoiesis? This knowledge could be instrumental in understanding dysregulated hematopoiesis, particularly in the setting of malignancy.

\section{ACCUMULATION OF MUTATIONS WITHIN THE NORMAL HSC AND PROGENITOR COMPARTMENT LEADS TO LEUKEMIA}

Most leukemia requires several mutations before transformation into a blast crisis. With the Majeti laboratory, we sought to understand the origin of these mutations by studying primary patient AML samples (Jan et al. 2012; Corces-Zimmerman et al. 2014). Knowing that the blast phase requires several mutations, we focused on how these were acquired and in what order they occurred by using advanced sorting and sequencing techniques.

First, we performed exome sequencing to identify known AML mutations. We then performed targeted resequencing and found that the mutations were present in a fraction of cells, which demonstrated that these were hemizygous mutations in a nonhomogenous population. When this was performed on phenotypic HSCs from leukemia patients, some but not all mutations were present in this subset, signifying that there were preleukemic cells within the HSC compartment (Jan et al. 2012).

This led us to perform single-cell sequencing to identify the order of clonal evolution in AML. In the HSC compartment, single or biallelic loss of TET2, a driver mutation, is observed at a high frequency. However, other driver mutations, like FLT3-ITD, which are seen in the primary leukemia blasts, were not observed in the HSC fraction. This suggests that the order of mutations acquired is not stochastic in AML. Preleukemic clones, which are phenotypically HSCs but harbor leukemiaassociated mutations, likely maintain mutations in the HSC pool through self-renewal. These clones then either outcompete healthy counterpart HSCs or are maintained within the HSC fraction at a similar frequency. Our single-cell mapping confirmed this and showed that additional mutations are slowly acquired in these preleukemic clones, eventually a mutation within the MPP is acquired and results in malignant transformation. In our samples, we were able to find additional evidence of clonal evolution in the HSC compartment by detecting other early mutation events in several individuals (e.g., mutation A-loss of TET2, A+B-loss of other TET2 allele, $\mathrm{A}+\mathrm{B}+\mathrm{C}$-minor mutation). This allowed us to make a roadmap from normal HSC to leukemia (Jan et al. 2012; Corces-Zimmerman et al. 2014).

This slow progression and maintenance of minor mutations within the HSC pool provides insight into both HSC and LSC biology. For example, because HSCs can self-renew and are maintained in vivo, the accumulation of mutations can occur slowly over time, which may be one reason why AML can affect an aging population (Estey and Dohner 2006; Estey 2006; Jan and Majeti 2013; Beerman et al. 2014). For some individuals, these mutations may provide a competitive advantage and begin to outcompete their remaining healthy HSCs (Corces-
Zimmerman et al. 2014). This clonal progression also provides insight into how to treat AML (or other blood malignancies) effectively. In some instances, a relapse may occur not because of residual disease but because of the accumulation of an alternate mutation in the progenitor population. In these instances, targeted therapies that will remove all blast, LSC, and preleukemic clones may be necessary (Majeti and Weissman 2011). We hypothesize that this sequential accumulation of mutations may also occur in other malignancies, such as solid tumors, and that their accumulation of mutation events can also be mapped in future studies to understand the progression of disease.

\section{PHENOTYPIC AND BIOLOGICAL DIFFERENCES BETWEEN THE HSC AND LSC}

AML was reported to be propagated by an LSC that was most likely an early progenitor, such as HSCs (Lapidot et al. 1994; Bonnet and Dick 1997). As described above, my laboratory has isolated and identified HSCs and early progenitors and demonstrated the functional differences of these populations (Muller-Sieburg et al. 1986; Kondo et al. 1997; Morrison et al. 1997; Akashi et al. 2000; Manz et al. 2002; Majeti et al. 2007; Mori et al. 2015). Using bone marrow from AML-1/ $\mathrm{ETO}^{+}$translocation leukemias, we determined what fraction gives rise to AML. We found that the $\mathrm{CD} 34^{+-}$ $\mathrm{CD} 38^{\text {lo }} \mathrm{CD}^{-} 0^{-} \mathrm{Lin}^{-} \mathrm{MPP}$ fraction propagates AML, whereas the HSC population, which still maintained the translocation, did not propagate the disease (Miyamoto et al. 2000). This suggested that the LSCs were more differentiated than the HSCs, as the two populations could give rise to two different phenotypes when transplanted into mice. These findings supported the idea that the LSCs are unique but maintain similar properties to the HSCs, as we had previously proposed (Reya et al. 2001).

To investigate the differences in more detail we relied on the fundamental findings that leukemia was self-perpetuating independently of the HSC population. These findings suggest that there is a pathway that is enriched in the progenitor LSC population that allows for the propagation of leukemia. We proposed that the wnt $\beta$-catenin pathway, and other pathways, were critical in the progression of LSCs and CSCs (Reya et al. 2001). We found that wnt3a and the $\beta$-catenin pathway regulate not only cell cycle but also self-renewal of HSCs, emphasizing the importance of this pathway in normal hematopoiesis (Reya et al. 2003). We explored this pathway in more detail when we investigated the progression of CML to blast crisis. Interestingly, the GMP population from CML patients in blast crisis had increased levels of nuclear $\beta$-catenin and had self-renewing capacity when compared with normal GMP populations (Jamieson et al. 2004a). In the chronic phase, BCR-ABL transcripts are also increased in the HSCs compared with myeloid progenitors; however, during the crisis phase, BCR-ABL was increased predominately in the myeloid progenitors, especially in the GMP population. During blast crisis the 
GMP-LSC is able to promote disease progression through the $\beta$-catenin pathway. We found that some of these patients had constitutively active $\beta$-catenin because of a splice variant, GSK3 $\beta$ that is expressed only in the GMP population (Abrahamsson et al. 2009). GSK3 $\beta$ is a critical factor of the destruction complex for $\beta$-catenin, and the splice variant of GSK3 $\beta$ lacked the capacity to phosphorylate $\beta$-catenin, allowing $\beta$-catenin to escape degradation and promote downstream signaling pathways. Additionally, we showed that when full-length GSK $3 \beta$ is re-expressed in the CML cells, $\beta$-catenin is decreased and leukemic engraftment is inhibited. This highlights the importance of GSK3 $\beta$ in the propagation of the LSC in CML, which propagates blast crisis from a progenitor downstream from the HSC. These data indicate that the HSC can harbor the mutation, and the mutations within the HSC may increase competiveness over nonmutant-bearing HSCs within the bone marrow. In all of the leukemias that we have evaluated, although we can detect mutations within the HSC population, they are completely distinct from the LSC, which is a downstream progenitor. Taken together, these findings indicate that although the mutation can be observed within HSCs, it is not until a later step that the leukemia arises owing to other contributing factors.

As discussed previously, in collaboration with the Majeti laboratory we determined what the progression is from HSCs to LSCs, to help identify potentially what the key differences are in the LSCs from the HSCs (Jan et al. 2012). Additionally, we found that there are mutations to the genetic landscape within the preleukemic HSCs that prime them for full leukemic transformation, which is observed in the LSCs' mutational load (CorcesZimmerman et al. 2014). Further analysis between HSCs and LSCs led us to identify dysregulated pathways in LSCs compared with HSCs (Majeti et al. 2009a). This type of analysis also led to the discovery that we could phenotypically isolate normal HSCs from preleukemic HSCs with the cell surface marker TIM3 (Jan et al. 2011) and identified a role for CD47 in both HSCs and LSCs (Jaiswal et al. 2009; Majeti et al. 2009b).

We have identified key mutations, signaling pathways, and surface markers for LSCs. This profile has allowed us and others to determine what the differences are between LSCs and HSCs. In short, we have demonstrated that LSCs are not HSCs but are downstream progenitors to HSCs that have acquired additional mutations. These additional mutations arise progressively in downstream progenitors, which influences survival signaling pathways and the up-regulation of the major "do not eat me" signal, CD47.

\section{IDENTIFYING CD47 AS A CELL SURFACE MOLECULE FOR INNATE IMMUNE EVASION}

We found that CD47 is transiently induced on normal HSCs providing protection to HSCs during inflammation-mediated mobilization (Jaiswal et al. 2009). This mechanism of temporary up-regulation in CD47 expres- sion serves an important physiological purpose but is hijacked by cancer cells as a method to evade the immune system.

CD47 is a ubiquitously expressed "do not eat me" signal, whose receptor, $\operatorname{SIRP} \alpha$, is expressed by macrophages. By comparing CD47 expression on LSCs with normal HSCs we discovered that CD47 is constitutively up-regulated in both mouse and human myeloid leukemia. We therefore hypothesized that the overexpression of CD47 on leukemic cells was a potential mechanism for allowing them to evade macrophage phagocytosis and increase their pathogenicity. By overexpressing CD47 in a mouse leukemia cell line, we were able to confirm this hypothesis, enhancing the engraftment of these cells in mice and demonstrating a direct correlation between the level of CD47 and the degree of pathology in the host. Conversely, by blocking CD47 on these cells with an antiCD47 antibody, we were able to restore the ability of macrophages to phagocytose the leukemic cells (Jaiswal et al. 2009).

When we extended our studies to multiple types of solid tumors we discovered that numerous cancer subtypes up-regulated CD47 on their surface. This was true for ovarian cancer, breast cancer, colon cancer, bladder carcinoma, hepatocellular carcinoma, prostate cancer, and glioblastoma (Willingham et al. 2012). By screening with in vitro phagocytosis assays in which we cocultured dissociated cells from human primary tumor samples with macrophages, we found that the addition of blocking anti-human CD47 (hCD47) mAbs significantly increased the efficiency of cancer cells phagocytosis by either human or mouse macrophages. When tested efficacy in NOD-scid- $\gamma$ (NSG) mouse xenotransplantation models, CD47 blockade increased the survival of the mice over time, preventing metastasis and inhibiting growth of larger tumors, while being potentially curative for smaller tumors (Willingham et al. 2012). Thus, we concluded that CD47 blockade could be a potent therapeutic strategy against many types of cancer.

Interestingly, despite the ubiquitous expression of CD47, macrophages did not engulf healthy cells from corresponding tissues even in the presence of high-dose anti-CD47 antibodies. Therefore, we postulated that there must be a prophagocytic "eat me" signal on cells that are destined for elimination by macrophages, and that such a recognition signal would be present on malignant cells in a tissue but not on their healthy counterparts. We identified calreticulin as one such signal, which is present on cancer stem cells and not on normal stem cells and acts as a robust "eat me" signal (Chao et al. 2010b).

Following this discovery, we began to investigate how calreticulin is trafficked to the surface of cancer cells. Calreticulin is an endoplasmic reticulum (ER) protein, which upon Toll-like receptor (TLR) activation is secreted by macrophages. It has been shown that TLR activation leads to Bruton's tyrosine kinase (BTK) signaling, which in turn phosphorylates calreticulin. Phosphorylated calreticulin is then cleaved to separate the KDEL domain, allowing macrophages to secrete soluble calreticulin. Soluble calreticulin then binds to tumor cells and to 
LRP1, a receptor for apoptotic cells, on macrophages and serves both as a recognition signal and as a tethering bridge between the macrophage and the tumor cell (Feng et al. 2015). Thus, calreticulin functions as a molecular "sensor" secreted by macrophages to label their targets for elimination. When a cancer cell is labeled with calreticulin but also expresses high levels of the "do not eat me" signal CD47-the antiphagocytic effect of the $\mathrm{CD} 47-\mathrm{SIRP} \alpha$ signaling axis can neutralize the macrophage, allowing the cancer cell to evade the innate immune system. However, with anti-CD47 blockade, this dynamic can be shifted, priming macrophages to clear malignant cells that they have recognized; this demonstrated the use of anti-CD47 blockade as an avenue for therapeutic intervention in enhancing the removal of malignant cells through immunotherapies.

Importantly, the effect of anti-CD47 blockade can also be used to help initiate an adaptive immune response. In a follow-up study, we found that anti-CD47 antibodymediated phagocytosis of cancer cells by macrophages can lead to priming of $\mathrm{CD}^{+} \mathrm{T}$ cells - measured by proliferation and activation. However, in our model these macrophages did not prime $\mathrm{CD}^{+}{ }^{+} \mathrm{T}$ cells, demonstrating potential differential priming of $\mathrm{T}$-cell responses by macrophages after anti-CD47 mediated phagocytosis. Priming an effective $\mathrm{CD} 8^{+} \mathrm{T}$ - cell response can help lead to durable long-term antitumor immunity. Therefore, the utilization of anti-CD47 as a modified "vaccination" strategy serves as a promising new avenue for the initiation of an antitumor T-cell response (Tseng et al. 2013).

These preclinical studies present an opportunity to utilize this finding for the development of novel cancer immunotherapy. We developed a humanized anti-CD47 antibody (Hu5F9-G4) with potent efficacy and favorable toxicokinetic properties as a candidate therapy. Administration of this antibody induced potent macrophage-mediated phagocytosis of primary human AML cells in vitro and completely eradicated human AML in xenotransplanted mouse models leading to long-term disease-free survival. Moreover, Hu5F9-G4 synergized with rituximab to eliminate non-Hodgkin's lymphoma (NHL) engraftment and cures xenografted mice (Chao et al. 2010a). Finally, toxicokinetic studies in nonhuman primates showed that Hu5F9-G4 could be safely administered intravenously at doses able to achieve potentially therapeutic serum levels in primates (Liu et al. 2015). Thus, Hu5F9-G4 has been entered into clinical trials in patients with AML and solid tumors (NCI trials NCT02678338 and NCT02216409; additional trials are anticipated).

In summary, our recent discovery of CD47 as an upregulated "do not eat me" signal on cancer is one mechanism by which they evade the immune system. These key studies have resulted in the development of a new cancer immunotherapy, utilizing blockade of CD47 with monoclonal antibodies and disrupting the CD47$\mathrm{SIRP} \alpha$ axis, resulting in cancer cell phagocytosis. We have also shown that there exist "eat me" signals, like soluble calreticulin secreted from macrophages. These discoveries have opened a major avenue of research exploring the mechanisms of recognition and clearance of target cells by phagocytes. Future studies will continue to understand the interplay of additional pro- and antiphagocytic pathways in various biological systems, with a fundamental aim to develop and identify ways to enhance programmed cell removal for effective anti-cancer therapy.

\section{CONCLUSION}

Normal and neoplastic stem cells share overlapping genetic programs for survival in vivo. In cancer, cells must acquire several additional key features to survive and transform into a malignancy. Our laboratory has studied several of these, but the work described here is focused on two key features - self-renewal and immune evasion.

For self-renewal, we identified the LSC population that was able to give rise to leukemia when transplanted into mice in vivo unlike blast cells that had little to no transplant capacity. These studies parallel initial BMT that utilized whole bone marrow and then was later refined to pHSCs. Through phenotypic sorting and transplantation of leukemic subpopulations, these experiments identified the tumorigenic cell population (LSC). Follow-up studies demonstrated that in the same primary patient sample, the HSC never contained the LSC population because HSCs only contained a fraction of the genetic mutations and the full oncogenic transformation occurred in downstream progeny.

For immune evasion, we looked again at LSCs and identified CD47 as a surface marker that was up-regulated. Similar to mobilized pHSCs that up-regulate CD47 to prevent being phagocytosed, the LSC population had constitutively high CD47 expression as a mechanism to avoid immune recognition and phagocytosis by macrophages. Our work then led us to develop an innate focused immunotherapy by targeting CD47 with a monoclonal antibody.

There are several similarities between normal and neoplastic stem cells as highlighted in the work above. By understanding what drives normal stem cells, we can begin to ask whether cancer acquires or maintains similar properties through mutual or distinct pathways. Therefore, the stem cell and/or cancer studies in our laboratory can provide mutual insight into the biology of both cell types and may lead to new approaches to improve cancer therapies.

\section{ACKNOWLEDGMENTS}

M.N.M is supported by the A.P. Giannini Foundation. I.L.W. is supported in part by the Virginia and D.K. Ludwig Fund for Cancer Research, and by a Stand Up To Cancer-Lustgarten Foundation Pancreatic Cancer Convergence Dream Team Translational Research Grant (grant number: SU2C-AACR-DT14-14). Stand Up To Cancer is a program of the Entertainment Industry Foun- 
dation administered by the American Association for Cancer Research.

\section{REFERENCES}

Abrahamsson AE, Geron I, Gotlib J, Dao KH, Barroga CF, Newton IG, Giles FJ, Durocher J, Creusot RS, Karimi M, et al. 2009. Glycogen synthase kinase $3 \beta$ missplicing contributes to leukemia stem cell generation. Proc Natl Acad Sci 106: 3925-3929.

Acar M, Kocherlakota KS, Murphy MM, Peyer JG, Oguro H, Inra CN, Jaiyeola C, Zhao Z, Luby-Phelps K, Morrison SJ. 2015. Deep imaging of bone marrow shows non-dividing stem cells are mainly perisinusoidal. Nature 526: 126-130.

Akashi K, Traver D, Miyamoto T, Weissman IL. 2000. A clonogenic common myeloid progenitor that gives rise to all myeloid lineages. Nature 404: 193-197.

Basch RS, Berman JW. 1982. Thy-1 determinants are present on many murine hematopoietic cells other than T cells. Eur $J$ Immunol 12: 359-364.

Baum CM, Weissman IL, Tsukamoto AS, Buckle AM, Peault B. 1992. Isolation of a candidate human hematopoietic stem-cell population. Proc Natl Acad Sci 89: 2804-2808.

Becker AJ, McCulloch EA, Till JE. 1963. Cytological demonstration of the clonal nature of spleen colonies derived from transplanted mouse marrow cells. Nature 197: 452-454.

Beerman I, Seita J, Inlay MA, Weissman IL, Rossi DJ. 2014 Quiescent hematopoietic stem cells accumulate DNA damage during aging that is repaired upon entry into cell cycle. Cell Stem Cell 15: 37-50.

Bonnet D, Dick JE. 1997. Human acute myeloid leukemia is organized as a hierarchy that originates from a primitive hematopoietic cell. Nat Med 3: 730-737.

Chao MP, Alizadeh AA, Tang C, Myklebust JH, Varghese B, Gill S, Jan M, Cha AC, Chan CK, Tan BT, et al. 2010a. AntiCD47 antibody synergizes with rituximab to promote phagocytosis and eradicate non-Hodgkin lymphoma. Cell 142: $699-713$

Chao MP, Jaiswal S, Weissman-Tsukamoto R, Alizadeh AA, Gentles AJ, Volkmer J, Weiskopf K, Willingham SB, Raveh T, Park CY, et al. 2010b. Calreticulin is the dominant prophagocytic signal on multiple human cancers and is counterbalanced by CD47. Sci Transl Med 2: 63ra94.

Chen JY, Miyanishi M, Wang SK, Yamazaki S, Sinha R, Kao KS, Seita J, Sahoo D, Nakauchi H, Weissman IL. 2016. Hoxb5 marks long-term haematopoietic stem cells and reveals a homogenous perivascular niche. Nature 530: $223-$ 227.

Chhabra A, Ring AM, Weiskopf K, Schnorr PJ, Gordon S, Le AC, Kwon HS, Ring NG, Volkmer J, Ho PY, et al. 2016. Hematopoietic stem cell transplantation in immunocompetent hosts without radiation or chemotherapy. Sci Transl Med 8: $351 \mathrm{ra} 105$

Christensen JL, Weissman IL. 2001. Flk-2 is a marker in hematopoietic stem cell differentiation: A simple method to isolate long-term stem cells. Proc Natl Acad Sci 98: 14541-14546.

Corces-Zimmerman MR, Hong WJ, Weissman IL, Medeiros BC, Majeti R. 2014. Preleukemic mutations in human acute myeloid leukemia affect epigenetic regulators and persist in remission. Proc Natl Acad Sci 111: 2548-2553.

Czechowicz A, Weissman IL. 2011. Purified hematopoietic stem cell transplantation: The next generation of blood and immune replacement. Hematol Oncol Clin N Am 25: 75-87.

Estey EH. 2006. General approach to, and perspectives on clinical research in, older patients with newly diagnosed acute myeloid leukemia. Semin Hematol 43: 89-95.

Estey E, Dohner H. 2006. Acute myeloid leukaemia. Lancet 368: $1894-1907$.

Fathman JW, Fernhoff NB, Seita J, Chao C, Scarfone VM, Weissman IL, Inlay MA. 2014. Upregulation of CD11A on hematopoietic stem cells denotes the loss of long-term reconstitution potential. Stem Cell Rep 3: 707-715.
Feng M, Chen JY, Weissman-Tsukamoto R, Volkmer JP, Ho PY, McKenna KM, Cheshier S, Zhang M, Guo N, Gip P, et al. 2015. Macrophages eat cancer cells using their own calreticulin as a guide: Roles of TLR and Btk. Proc Natl Acad Sci 112: $2145-2150$.

Ford CE, Hamerton JL, Barnes DW, Loutit JF. 1956. Cytological identification of radiation-chimaeras. Nature 177: 452454.

Gazit R, Mandal PK, Ebina W, Ben-Zvi A, Nombela-Arrieta C, Silberstein LE, Rossi DJ. 2014. Fgd5 identifies hematopoietic stem cells in the murine bone marrow. J Exp Med 211: 13151331

Hills D, Gribi R, Ure J, Buza-Vidas N, Luc S, Jacobsen SE, Medvinsky A. 2011. Hoxb4-YFP reporter mouse model: A novel tool for tracking HSC development and studying the role of Hoxb4 in hematopoiesis. Blood 117: 3521-3528.

Hosen N, Yamane T, Muijtjens M, Pham K, Clarke MF, Weissman IL. 2007. Bmi-1-green fluorescent protein-knock-in mice reveal the dynamic regulation of bmi-1 expression in normal and leukemic hematopoietic cells. Stem Cells 25: 1635-1644.

Ikuta K, Weissman IL. 1992. Evidence that hematopoietic stem cells express mouse c-kit but do not depend on steel factor for their generation. Proc Natl Acad Sci 89: 1502-1506.

Jacobson LO, Simmons EL, Marks EK, Eldredge JH. 1951. Recovery from radiation injury. Science 113: 510-511.

Jaiswal S, Jamieson CH, Pang WW, Park CY, Chao MP, Majeti $\mathrm{R}$, Traver D, van Rooijen N, Weissman IL. 2009. CD47 is upregulated on circulating hematopoietic stem cells and leukemia cells to avoid phagocytosis. Cell 138: 271-285.

Jamieson CH, Ailles LE, Dylla SJ, Muijtjens M, Jones C, Zehnder JL, Gotlib J, Li K, Manz MG, Keating A, et al. 2004a. Granulocyte-macrophage progenitors as candidate leukemic stem cells in blast-crisis CML. N Engl J Med 351: 657-667.

Jamieson CH, Weissman IL, Passegue E. 2004b. Chronic versus acute myelogenous leukemia: A question of self-renewal. Cancer Cell 6: 531-533.

Jan M, Majeti R. 2013. Clonal evolution of acute leukemia genomes. Oncogene 32: 135-140.

Jan M, Chao MP, Cha AC, Alizadeh AA, Gentles AJ, Weissman IL, Majeti R. 2011. Prospective separation of normal and leukemic stem cells based on differential expression of TIM3, a human acute myeloid leukemia stem cell marker. Proc Natl Acad Sci 108: 5009-5014.

Jan M, Snyder TM, Corces-Zimmerman MR, Vyas P, Weissman IL, Quake SR, Majeti R. 2012. Clonal evolution of preleukemic hematopoietic stem cells precedes human acute myeloid leukemia. Sci Transl Med 4: 149ra118.

Kiel MJ, Yilmaz OH, Iwashita T, Yilmaz OH, Terhorst C, Morrison SJ. 2005. SLAM family receptors distinguish hematopoietic stem and progenitor cells and reveal endothelial niches for stem cells. Cell 121: 1109-1121.

Kondo M, Weissman IL, Akashi K. 1997. Identification of clonogenic common lymphoid progenitors in mouse bone marrow. Cell 91: 661-672.

Lapidot T, Sirard C, Vormoor J, Murdoch B, Hoang T, CaceresCortes J, Minden M, Paterson B, Caligiuri MA, Dick JE. 1994. A cell initiating human acute myeloid leukaemia after transplantation into SCID mice. Nature 367: 645-648.

Liu J, Wang L, Zhao F, Tseng S, Narayanan C, Shura L, Willingham S, Howard M, Prohaska S, Volkmer J, et al. 2015. Preclinical development of a humanized anti-CD47 antibody with anti-cancer therapeutic potential. PLoS One 10: e0137345.

Lorenz E, Uphoff D, Reid TR, Shelton E. 1951. Modification of irradiation injury in mice and guinea pigs by bone marrow injections. J Natl Cancer Inst 12: 197-201.

Majeti R, Weissman IL. 2011. Human acute myelogenous leukemia stem cells revisited: There's more than meets the eye. Cancer Cell 19: 9-10.

Majeti R, Park CY, Weissman IL. 2007. Identification of a hierarchy of multipotent hematopoietic progenitors in human cord blood. Cell Stem Cell 1: 635-645.

Majeti R, Becker MW, Tian Q, Lee TL, Yan X, Liu R, Chiang JH, Hood L, Clarke MF, Weissman IL. 2009a. Dysregulated 
gene expression networks in human acute myelogenous leukemia stem cells. Proc Natl Acad Sci 106: 3396-3401.

Majeti R, Chao MP, Alizadeh AA, Pang WW, Jaiswal S, Gibbs KD Jr, van Rooijen N, Weissman IL. 2009b. CD47 is an adverse prognostic factor and therapeutic antibody target on human acute myeloid leukemia stem cells. Cell 138: 286-299.

Manz MG, Miyamoto T, Akashi K, Weissman IL. 2002. Prospective isolation of human clonogenic common myeloid progenitors. Proc Natl Acad Sci 99: 11872-11877.

Mendez-Ferrer S, Michurina TV, Ferraro F, Mazloom AR, MacArthur BD, Lira SA, Scadden DT, Ma'ayan A, Enikolopov GN, Frenette PS. 2010. Mesenchymal and haematopoietic stem cells form a unique bone marrow niche. Nature 466: 829-834.

Miyamoto T, Weissman IL, Akashi K. 2000. AML1/ETOexpressing nonleukemic stem cells in acute myelogenous leukemia with 8;21 chromosomal translocation. Proc Natl Acad Sci 97: 7521-7526.

Mori Y, Chen JY, Pluvinage JV, Seita J, Weissman IL. 2015. Prospective isolation of human erythroid lineage-committed progenitors. Proc Natl Acad Sci 112: 9638-9643.

Morrison SJ, Wandycz AM, Hemmati HD, Wright DE, Weissman IL. 1997. Identification of a lineage of multipotent hematopoietic progenitors. Development 124: 1929-1939.

Muller AM, Kohrt HE, Cha S, Laport G, Klein J, Guardino AE, Johnston LJ, Stockerl-Goldstein KE, Hanania E, Juttner C, et al. 2012. Long-term outcome of patients with metastatic breast cancer treated with high-dose chemotherapy and transplantation of purified autologous hematopoietic stem cells. $J$ Am Soc Blood Marrow Transpl 18: 125-133.

Muller-Sieburg CE, Whitlock CA, Weissman IL. 1986. Isolation of two early B lymphocyte progenitors from mouse marrow: A committed pre-pre-B cell and a clonogenic Thy-1-lo hematopoietic stem cell. Cell 44: 653-662.

Osawa M, Hanada K, Hamada H, Nakauchi H. 1996. Long-term lymphohematopoietic reconstitution by a single CD34-low/ negative hematopoietic stem cell. Science 273: 242-245.

Reya T, Morrison SJ, Clarke MF, Weissman IL. 2001. Stem cells, cancer, and cancer stem cells. Nature 414: 105-111.

Reya T, Duncan AW, Ailles L, Domen J, Scherer DC, Willert K, Hintz L, Nusse R, Weissman IL. 2003. A role for Wnt signalling in self-renewal of haematopoietic stem cells. Nature 423: 409-414.

Russell ES. 1979. Hereditary anemias of the mouse: A review for geneticists. Adv Genet 20: 357-459.

Seita J, Weissman IL. 2010. Hematopoietic stem cell: Self-renewal versus differentiation. Wiley Interdiscip Rev Syst Biol Med 2: 640-653.
Seita J, Sahoo D, Rossi DJ, Bhattacharya D, Serwold T, Inlay MA, Ehrlich LI, Fathman JW, Dill DL, Weissman IL. 2012. Gene Expression Commons: An open platform for absolute gene expression profiling. PLoS One 7: e40321.

Smith LG, Weissman IL, Heimfeld S. 1991. Clonal analysis of hematopoietic stem-cell differentiation in vivo. Proc Natl Acad Sci 88: 2788-2792.

Spangrude GJ, Johnson GR. 1990. Resting and activated subsets of mouse multipotent hematopoietic stem cells. Proc Natl Acad Sci 87: 7433-7437.

Spangrude GJ, Heimfeld S, Weissman IL. 1988. Purification and characterization of mouse hematopoietic stem cells. Science 241: $58-62$.

Susaki EA, Tainaka K, Perrin D, Kishino F, Tawara T, Watanabe TM, Yokoyama C, Onoe H, Eguchi M, Yamaguchi S, et al. 2014. Whole-brain imaging with single-cell resolution using chemical cocktails and computational analysis. Cell 157: $726-739$.

Thomas ED, Lochte HL Jr, Lu WC, Ferrebee JW. 1957. Intravenous infusion of bone marrow in patients receiving radiation and chemotherapy. New Engl J Med 257: 491-496.

Thomas ED, Lochte HL Jr, Cannon JH, Sahler OD, Ferrebee JW. 1959. Supralethal whole body irradiation and isologous marrow transplantation in man. J Clin Invest 38: 17091716.

Till JE. 1961. Radiosensitivity and chromosome numbers in strain L mouse cells in tissue culture. Radiat Res 15: 400409.

Tseng D, Volkmer JP, Willingham SB, Contreras-Trujillo H, Fathman JW, Fernhoff NB, Seita J, Inlay MA, Weiskopf K, Miyanishi M, et al. 2013. Anti-CD47 antibody-mediated phagocytosis of cancer by macrophages primes an effective antitumor T-cell response. Proc Natl Acad Sci 110: 1110311108.

Uchida N, Fleming WH, Alpern EJ, Weissman IL. 1993. Heterogeneity of hematopoietic stem cells. Curr Opin Immunol 5: $177-184$.

Whitlock CA, Witte ON. 1982. Long-term culture of B lymphocytes and their precursors from murine bone marrow. Proc Natl Acad Sci 79: 3608-3612.

Willingham SB, Volkmer JP, Gentles AJ, Sahoo D, Dalerba P, Mitra SS, Wang J, Contreras-Trujillo H, Martin R, Cohen JD, et al. 2012. The CD47-signal regulatory protein $\alpha$ (SIRPa) interaction is a therapeutic target for human solid tumors. Proc Natl Acad Sci 109: 6662-6667.

Wu AM, Till JE, Siminovitch L, McCulloch EA. 1967. A cytological study of the capacity for differentiation of normal hemopoietic colony-forming cells. J Cell Physiol 69: 177184. 


\section{$\$_{\text {CSH\& }}^{\infty}$ Cold Spring Harbor Symposia SYMPOSIA On Quantitative Biology}

\section{Normal and Neoplastic Stem Cells}

Melissa N. McCracken, Benson M. George, Kevin S. Kao, et al.

Cold Spring Harb Symp Quant Biol 2016 81: 1-9 originally published online April 17, 2017 Access the most recent version at doi:10.1101/sqb.2016.81.030965

References This article cites 65 articles, 25 of which can be accessed free at: http://symposium.cshlp.org/content/81/1.full.html\#ref-list-1
Creative This article is distributed under the terms of the
Commons http://creativecommons.org/licenses/by-nc/4.0/, which permits reuse and License redistribution, except for commercial purposes, provided that the original author and source are credited.

Email Alerting
Service $\quad \begin{aligned} & \text { Receive free email alerts when new articles cite this article - sign up in } \\ & \text { the box at the top right corner of the article or click here. }\end{aligned}$ 